\title{
The best-kept secret(s) of evidence based policing
}

\section{Abstract}

The paper draws on the work of the Evidence and Insight Team, a dedicated research function based within the Metropolitan Police Service for over a decade. The aim of the paper is to make readers aware of the obliquely hidden data goldmine that exists within UK policing. Such data captures the decisions police make routinely, the kinds of situations police encounter and with whom. This rich data seam goes beyond crime - and should be used more outside of policing. The authors argue that interested academics need a better roadmap of the data in order to stimulate basic knowledge and usage. Three case studies are presented that illustrate the scope and challenges of working with such data.

\section{Introduction}

Evidence Based Policing ${ }^{\mathrm{i}}$ (EBP) is currently a popular term - not only with police forces, but also wider government. It is not a new term, far from it, and the current ground swell for its use provides the "best opportunity to embed EBP in a generation" "ii. However, the challenges of embedding Evidence Based Policing into any police organisation are complex, and numerous academic scholars (overwhelmingly based outside of the organisation) have described these challenges as resistance to change. Scholars include descriptions of cultures inside policing (such as machismo, action-orientated work and internal loyalty) which too often supports scepticism of social science research ${ }^{\text {iii }}$. Last year the authors of this paper released a monograph ${ }^{\text {iv }}$ that set out a uniquely pragmatic perspective on this issue, and one that was based on over a decade of working within the police sharing the work of the Evidence and Insight Team - the largest dedicated civilian research team within policing (or Policing and Crime Commissioner's Office) in the UK.

In our opinion, there is a sense of irony in many of the Evidence Based Policing discussions here and abroad. Whilst there are many (laudable) debates on promoting gold standard methodologies or research training for policing (that largely focus on external agencies or universities conducting original primary research), these discussions largely overlook the wealth data that is routinely captured within police forces that should be the mainstay information for any new research. 
The purpose of this paper is to make readers aware of the largely hidden data goldmine that exists within UK policing. Captured routinely ${ }^{\mathrm{v}}$, many scholars are unaware that the data exists in the first place, and as we will see, even this most basic of steps is an oblique challenge to turn organisational information into substantive and reliable data. There are no easy-to-understand research guides or publications outlining police data and what it can, and cannot, offer to a researcher. Even if researchers identify information held by police to build a picture of phenomena, it does not always follow that they will be allowed to use the information. Transparency still has a long way to go. Through a number of case studies, we will illustrate not only the eclectic scope of data captured by routine police work, but also the challenges in using such data. Many speak of the limitations of police data - this is true! However, as insiders we have learned not to treat data as gospel but as what it is organisational data. An organisational record of knowledge - and one that is brimming with potential, enabling theoretical discussions to be grounded in the way police work ${ }^{\mathrm{vi}}$.

The article is aimed at any student or researcher with an interest in conducting research into/with policing. Moreover, the data that are routinely collected go far beyond what many would consider as 'police data' (i.e., crime) and includes far, far more about organisational decision-making, internal bias and the nature of problems brought to police attention. You may not even have to be all that interested in "policing" to want to use police data. Budding researchers exploring issues as diverse as mental health, missing people, vulnerability, public perceptions, criminal careers and many more will find a rich seam of information. The hope of the authors is that we attract more use of this information within this neglected area of Evidence Based Policing.

\section{An inside job - the Evidence and Insight team}

It may come as a surprise to readers to know that a police service - here the London Metropolitan Police Service (MPS) had an internal academic research function for over a decade. Whilst there were 'evidence flickers' before ${ }^{\text {vii }}$, the push fully begin in 2000 driven by Professor Stanko and continued to thrive until 2014, upon which time the developed team of social researchers migrated to the Mayor's Office for Policing And Crime

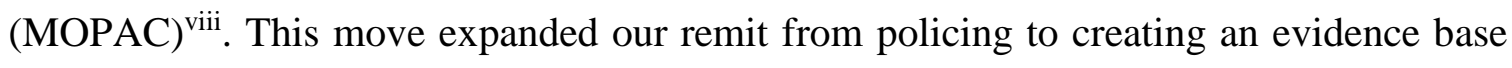
for policy on crime and justice for London. We maintain our links and data access with the 
MPS. This insider perspective has proved unique - not just in knowing and using police data, but beyond these into a first hand understanding managing improvements and juggling police culture, performance pressures, hierarchy, implementation, training and information flow at the same time. This has enabled us to bring a uniquely internal voice to many of the current evidence based policing and crime discussions.

Moving to the present time, the work of the Evidence and Insight team is large and varied bringing a mixture of original research and innovative analysis of police and other justice data - but broadly is captured by:

1) Conducting a range of high quality research/evaluation, ranging from large scale Randomised Control Trials (i.e., on Body Worn Video) to smaller scale evaluations (i.e., the Alcohol Abstinence Monitoring Requirement (AAMR)) to bespoke problem profiles (mixing performance and social research) ${ }^{\mathrm{ix}}$.

2) An expertise in survey design to capture the voice of Londoners. The team oversees a wealth of surveys - from large scale (e.g., The Public Attitude Survey (PAS)) or the User Satisfaction Survey (USS) - each with approximate 14,000 responses a year) to smaller scale ${ }^{\mathrm{x}}$. We conducted the PAS and USS whilst in the MPS and continue to do so at MOPAC.

3) Expert Performance analysis and data visualisation. There is a strong performance aspect in monitoring key MOPAC objectives, both internal to MOPAC and the MPS but also externally through a suite of Dashboards, the London Landscape and MOPAC Challenges that enable innovative accountability of key topics ${ }^{\mathrm{xi}}$.

4) Develop and manage a network of academics, enabling MOPAC to draw on key academic knowledge and expertise to aid decision-making, as illustrated by The Institute for Global City Policing; The London Landscape or the Global Policing Database $e^{\mathrm{xii}}$.

It is through the work and experience of the Evidence and Insight - both our past work in the MPS and new examples of our work whilst at MOPAC that we will draw upon for the remainder of the paper. 


\section{A data 'goldmine' for researchers}

A selection of the systems held by the MPS is outlined in table 1 . These are operational systems essential to the craft of policing; yet they are able to act as a valuable data source for analysis. This is not a definitive list of data systems, but rather an overview. A glance at the table will reveal data sets on issues such as crime types, victims, witnesses, suspects, crime locations, vulnerability, missing people, gangs and stop and search. Depending upon the specific data in question, information could be available over time, at a pan-London, borough or even individual level. Indeed, beyond the systems presented, there are others capturing data ranging from public complaints, taser-use, officer misconduct, all the way to workforce numbers. The scope is dizzying - then consider these data sets can often be overlaid to gain deeper insights.

As an illustration, take sexual assault/rape - one could look at the basics around number of calls to the police, number of arrests, charges or offences over time, (and the conversion from one to another ${ }^{x i i i}$, borough variation and change over time on these basics, hotspot locations of the offences, victim attrition through the system, victim characteristics and vulnerabilities, repeat victimisation, offender characteristics, offender criminal history, offender crime scene behaviours (e.g., weapon use or injury) and crime linking. These are illustrations and there are more, the point is this is an enviable data rich position and areas of criminology, law, forensic psychology, investigative psychology and others should take note of the possibilities.

At our most optimistic, it is also possible that these data sets could be combined with nonMPS data. Partner information sharing is still not routine (e.g., complex legal agreements to share and lack of unique identifiers muddy the ability to share) but it will be increasingly possible to look at phenomena in the round. For example, following the disorders of 2011, government researchers were able to examine individual offending histories on offenders (e.g., PNC) merging Department of Work and Pensions and Department of Education information to gain far wider insights about backgrounds and social needs of those arrested offenders. 
Returning to the knowledge and use of police data - if the scope is so broad, there is a question as to why the data is not used more within academia. One reason may be the uneasy relationship between police and academic researcher(s), tensions that have been noted by a number of scholars ${ }^{\mathrm{xiv}}$. Indeed, one of the authors has previously outlined "it is no exaggeration that a typical police force holds a veritable goldmine of data ripe for in depth examination by researchers. That the [negative/tense] relationship between research and police may result in these data not being used to its full potential is a desperate shame for both parties ${ }^{\prime x v}$.

Table 1. Example of MPS data systems 


\begin{tabular}{|c|c|}
\hline $\begin{array}{l}\text { Crime Recording Information System } \\
\text { (CRIS) } \\
\text { https://www.london.gov.uk/moderngov/../s36836/Appendix } \% 20 \\
\text { 12a.pdf }\end{array}$ & $\begin{array}{l}\text { Crime, victim, witness, suspect, dates, } \\
\text { location, venue, variety of information flags } \\
\text { (eg., mental health) }\end{array}$ \\
\hline $\begin{array}{l}\text { Computer Aided Dispatch (CAD) } \\
\text { https://en.wikipedia.org/wiki/Central_Communications_C } \\
\text { ommand }\end{array}$ & Calls into the Police, attendance, demand \\
\hline $\begin{array}{l}\text { MERLIN } \\
\text { http://www.met.police.uk/foi/pdfs/disclosure_2014/nove } \\
\text { mber_2014/2014070001191.pdf }\end{array}$ & $\begin{array}{l}\text { Vulnerable adults and children, missing } \\
\text { people }\end{array}$ \\
\hline $\begin{array}{l}\text { Stops database } \\
\text { http://www.met.police.uk/foi/pdfs/priorities_and_how_we } \\
\text { are doing/corporate/mps stop and search impact.pdf }\end{array}$ & $\begin{array}{l}\text { Stop and Search, Stop and account, } \\
\text { aggregate and individual levels }\end{array}$ \\
\hline $\begin{array}{l}\text { Crimint } \\
\text { http://www.met.police.uk/foi/pdfs/disclosure_2013/nove } \\
\text { mber_2013/2013100000403.pdf }\end{array}$ & Data on police intelligence \\
\hline $\begin{array}{l}\text { Police National Computer (PNC) } \\
\text { https://www.gov.uk/government/uploads/system/uploads/ } \\
\text { attachment_data/file/488515/PNC_v5.0_EXT_clean.pdf }\end{array}$ & Offending history \\
\hline $\begin{array}{l}\text { NSPIS } \\
\text { http://www.met.police.uk/foi/pdfs/disclosure_2014/may_ } \\
\text { 2014/2014040000418.pdf }\end{array}$ & Custody information \& demand \\
\hline $\begin{array}{l}\text { Electronic Warrant Management } \\
\text { Systems (EWMS) } \\
\text { http://www.met.police.uk/foi/pdfs/policies/wanted_offend } \\
\text { er_eia2013.pdf }\end{array}$ & Wanted offenders \\
\hline $\begin{array}{l}\text { Trident Command Gang Matrix } \\
\text { http://www.met.police.uk/foi/pdfs/disclosure_2014/octob } \\
\text { er 2014/2014050000906.pdf }\end{array}$ & Gang data \\
\hline
\end{tabular}

However, the first step is to know the data exists - and this most basic of steps is perhaps the largest challenge facing academics and other interested individuals. Information on these systems only appears to be obliquely available on the internet (more is available on 
the Police National Computer). As part of table 1 we include links providing examples of some information now in the public domain through Freedom of Information requests. Of course, these data are drawn from operational databases holding sensitive data, and not all researchers would gain access to harvesting this information direct from police systems. The lack of transparency (in the form of basic descriptions of what these systems are and what information they hold) hinders analytic output, academic cooperation and perhaps even fuels wider public scepticism around the police and accountability.

We understand this is a difficult balance; however, there is learning from other police forces that we feel strike a better balance. To illustrate, one of the authors ${ }^{\mathrm{xvi}}$ has used official data in the form of Violent Crime Linkage System (ViCLAS) - a Canadian police system originating in the 1980s that captures data on a range of violent and sexual offences and is now used by many police forces. It is essentially a searchable repository to capture, collate and compare violent crime. The point is that the ViCLAS booklet (e.g., information/training on all the data collected) is quite rightly not in the public domain due to investigative sensitivities - but official, clear, easy to find information on what the system is, who can use it, how to go about access and related research is available ${ }^{\mathrm{xvii}}$.

On the contrary, there does not seem to be any 'official' police data documented toolkits (or even description) of what each of the data systems are and what they can offer. Transparency does not appear to have reached knowledge about even these data systems in themselves. A university researcher would be hard pressed to know what was available or even where to look! Without such a toolkit and publicity, Evidence Based Policing will remain a closed shop to a select few - accessible to those who already know about it (typically the relatively small number of officers that seek academic qualifications). We are interested in widening access, of course alongside a process ensuring issues such as data protection; security and vetting are responsibly addressed. Indeed, one of our team functions whilst based within the MPS was to be the gatekeeper of the data and facilitate external researchers that were seeking to obtain data. Many police forces are beginning to facilitate requests for information brigaded under College of Policing's continuous push for generating better knowledge to benefit policing. 
Researchers must also be realistic about 'flaws' in police organisation data fed by issues of police data quality and integrity. Much has been written on this topic and we do not wish to repeat these ${ }^{\mathrm{xviii}}$ around how crimes are recorded, improper pressures in recording, the impact upon victims, and public trust in crime statistics. Indeed, the recent letter ${ }^{x i x}$ from Sir Thomas Winsor to all Chief Constables in November 2015 (and Police and Crime Commissioners) reiterated the above problems as part of a data integrity inspection programme.

We wholeheartedly agree with this approach, not for data's sake, but for the management of policing in any local region! However, as research insiders, as those that work with much of the data ourselves, we have come to appreciate both what the data can and cannot tell us analytically. To not see it as gospel (such as using the information to quote exact numbers of kinds of crimes), but as data - and all data is flawed. As researchers and those who analyse the data we often check our expectations so they are not raised to unrealistic levels given the 'official' source. Remember, the data quality is dependent on everything from offenders giving correct details, victims remembering, data entered correctly and so on. We are not excusing these recurring data issues, rather pragmatically working with what we have because these data colour the approach police have to a problem (how 'big' is it?; how complex?; has it grown or decreased?): which still remains an organisational record of knowledge and one that brims with potential in the generation of insights.

\section{Beyond the data - wider opportunities for those interested in police research}

As one will appreciate, the scope of data is impressive and goes beyond crime data per se into a range of other topics. As said earlier, one doesn't necessarily need to be interested in policing to find data of interest within the police. This may surprise readers - we sincerely hope it does. However, for those who are interested in policing there are more opportunities than just the data. We would like to draw attention to some of these. You may be interested in first hand primary research and in this case it may be possible to work with police as $a$ research sample(s) (e.g., interviews, observations). This is a regular facet of our research. On a related theme, the police could be viewed as gatekeepers - in that they may provide 'ins', not only to police data, but wider groups (e.g., community groups) and data (e.g., police social media twitter data). Finally, there are research active officers and others that 
seek to commission research. For any budding evidence based researcher, these are your allies.

\section{Examples of our work drawing from Police data}

We next present three brief case studies of projects we have completed utilising police data. The aim is to illustrate the depth of data available - but also the limitations. As we will demonstrate, working with police data can be both simultaneously empowering and frustrating.

\section{1) Mental Health and the Police ${ }^{x x}$}

Over the years there have been many calls to improve how the police understand and manage individuals with mental health problems ${ }^{\mathrm{xxi}}$. One of the latest of such calls for action in the UK came about subsequent to the death of Sean Rigg in 2008. Sean was a Black British musician/producer with a history of paranoid schizophrenia whom died in police custody in a South London police station. The inquest into the death highlighted numerous failings within the police - such as the use of unnecessary police force during restraint. In 2012 an Independent commission was established, led by Lord Victor Adebowale, into how the MPS responds to policing incidents involving mental health. Stanko was a member of the Commission.

To support the Commission, Evidence and Insight were asked to produce a problem profile

of mental health and the police ${ }^{x x i i}$. Our starting point was to focus on what was routinely collected as well as original social research. We looked at considerable data from how quickly the police respond to mental health calls, victim satisfaction to the criminal careers of offenders with a mental health issue. The key results were:

1. Through initial calls for service data (Computer Aided Despatch) and recorded crime records (Crime Recording Information System) we were able to examine the number of calls/crimes coming to the police that were flagged as linked to mental health. In total an average of 165 calls per day were recorded as related to people with mental health issues, showing clear geographic borough variation. We also saw a clear rise in reporting. Perhaps surprisingly, $25 \%$ of these calls were logged as 'general chat or 
advice' raising queries to us about training/referral frameworks when handling such potentially vulnerable callers.

2. Using MERLIN we were able to identify an average of 203 patients each month reported from absconding from a (psychiatric) hospital to the police.

3. Examining official Taser deployment figures between Sept 2011 and August 2012 we found that over a third of the 231 deployments were linked to mental health in some way.

4. We conducted original surveys of staff (Borough Mental Health Liaison Officers and other response officers); findings echoed previous studies indicating inadequate training around identification, needs and management of mental health. Wider surveys, drawing upon our London surveys of Offender Management revealed gaps in terms of appropriate access to mental health partners.

Our final reflections were that we had only scratched the surface of understanding mental health and the police, and the quality of captured data was not empowering easy insights. For example, we encountered paper forms that were being used to document important, rich information about the difficulties in handovers between police and the health service. We also found that this was an understatement, as we also documented the gap between the use of the mental health flags (alerts) on CRIS and evidence that these alerts were not being reliably used. We learned a lot within the profile, but with improved collection, more could have been gleaned. If we were mental health professionals, we would be able to learn much more using police data.

\section{2) Technology and the MPS - Body Worn video (BWV)}

There is a compelling case for police officers to wear Body Worn Video - both from previous research demonstrating benefits around reducing complaints to wider discussions around police transparency. When in 2014 the MPS and MOPAC sought to start a pilot of the technology, there was the opportunity to conduct the largest urban randomised test of the technology in the world. Quite the opportunity. The aim of the current paper is not to 
discuss the whole research ${ }^{\mathrm{xxiii}}$ - but rather demonstrate the range of outcomes we were able to track using police data. These included:

1. Using police systems to track a range of basic performance data on the technology (such as actual usage or amount of evidential footage recorded).

2. The number of complaints made to the officers wearing and not wearing the technology.

3. The number of Stops and Searches conducted (and the outcome) for the officers wearing and not wearing the technology.

4. The number of arrests and charges made by the officers wearing and not wearing the technology.

5. A sample of over 4000 victims of crime from the existing survey of crime victims (User Satisfaction Survey) as to whether they were more or less satisfied when dealt with by officers wearing BWV.

6. Over 12,000 Londoners from the already existing survey of the public (the Public Attitude Survey) and their views on the technology.

7. Online surveys of individual officers (both that had the technology and those without) asking their views.

The overall results of the trial showed some evidence that BWV could reduce the number of allegations (particularly against oppressive behaviour complaints), and the public were very positive around the technology - although on all other measures there was no significant change/difference. It should be stated that these results do not demonstrate that BWV failed as an approach or doesn't have the potential to bring about positive differences. Indeed, since our work there has been other research demonstrating positive BWV findings ${ }^{\mathrm{xxiv}}$. The reasons for our results largely come down to something we have written extensively about elsewhere ${ }^{\mathrm{xx}}$ - implementation. Implementing anything is difficult, implementing innovation even more so. BWV is a good example of this challenge. There were many teething problems: issues in the training, set-up, shortfalls of camera numbers and (potentially because of these) mixed usage. Indeed, a quarter of officers (26\%) recorded less than five active clips per month and six percent uploaded nothing at all! Finally, and perhaps most damning we had no clear start date for the research as we were 
not able to obtain the actual date an officer received their BWV camera - which succinctly illustrates the type of practical frustration encountered using police data ${ }^{\mathrm{xxvi}}$.

\section{3) Layering police data after the 2011 disorder}

Following the disorder of 2011 , described as 'the most widespread outbreaks of disorder seen in England for a generation' - we conducted a range of analysis that contributed to the MPS's own internal review. For the current example, we outline one aspect of our analysis that explored the offending histories of those arrested during the disorder, notable as we overlaid numerous MPS systems to gain better insights and wrapped up the package within a conceptual framework around procedural justice ${ }^{\mathrm{xxvii}}$.

In this analysis, we obtained full Police National Computer data on those arrested in the disorder $^{\text {xxviii }}$ - analysis was on a total of 2478 individuals. From this we were able to explore the basic demographics, e.g., $88 \%$ were male, $56 \%$ Black ethnic appearance and $12 \%$ were foreign nationals. Even at the demographics level there were insights, for example the females arrested tended to be older than the males, or older arrestees were more likely to be white.

In terms of criminal history, $29 \%$ of arrestees were defined as first time offenders with $71 \%$ having a previous sanction (e.g., conviction, caution, reprimand or warning). Of those with a previous sanction, $41 \%$ received their first one prior to the age of 16 and $68 \%$ before their 18th birthday. Only $36 \%$ of arrestees received their most recent sanction in the year prior to the disorder, indicating that many 'had form' but were not particularly criminally active leading upto the disorder. On average arrestees had sanctions for eight previous offences (range 0-207). Comparing these results to national criminal statistics placed this arrestee group as more criminal than the general adult or youth population but less prolific than offenders sentenced for indictable offences in 2010/11. We also sought to learn more by merging the various police systems - we overlaid information on gangs on top of what we already had. This revealed that $19 \%$ of arrestees had known links to gangs. These gang arrestees tended to be younger, more likely to have a sanction, received their first sanction at a younger age and were more likely to have a serous offence in their history. 
Finally, we overlaid stop and search information. A total of $65 \%(n=1614 / 2478)$ of arrestees were able to be matched to the stop and search data. Of those that could be matched, we found half had been stopped by police on at least one occasion in the year prior. Ten per cent had been stopped on five or more occasions. Two per cent had been stopped on 10 or more occasions. Gang members and those with a recent sanction were the individuals most likely to have been stopped and searched, although many individuals with no offending history prior to the disorder were still stopped. In our paper we reflected on the importance of the stop encounter and offender management for this group of arrestees moving forward. What this means is that we were able to generate a more rounded, multimethod understanding of who were arrested for disorder, leading to policy discussions about what kinds of interventions may need to be put in place in order to avoid such a situation in the future.

\section{Wrap up and wider reflections}

Many scholars shun the use of police data, or court data, as this routinely generated institutional account may not provide the depth of understanding about issues facing the criminal justice system and the role of law in this. These data described above however do capture the kinds of categories of decisions police make routinely, the kinds of situations police encounter routinely, and with whom. Of course there is much not recorded in police accounts. Indeed, much of policing relies on an oral tradition that intensive observational studies are fundamental to understanding how police work.

That said, there is much lost if we fail to recognise the organisational perspectives found within these data. Decades ago, ethnomethodologists ${ }^{\mathrm{xxix}}$ studied the routine decisions of state agents (common sense making). An appreciation of the context of policing, the cultures within which legal decisions are made, the bond of the profession, and its persistent oral tradition must go alongside the use of police data too.

Both of us have learned however that police information is a rich seam; good insights are possible to draw from creative analytic work. Allies exist within the policing profession. The transparency agenda is slowly taking hold. These all point to a better climate for work 
within a previously hidden world. We encourage readers to explore these avenues for information.

\section{References}

Bradley, K. (2009). The Bradley Report: Lord Bradley's review of people with mental health problemsor learning disabilities in the criminal justice system. London: Department of Health.

Chan, J. (1997). Changing police culture: Policing in a multicultural society. Cambridge: Cambridge University Press.

Cope, N. (2004). “Intelligence led policing or policing led intelligence?” Integrating volume crime analysis into policing. The British Journal of Criminology, 44, 188-203. 
Dawson, P., \& Stanko, B. (2013). Implementation, implementation, implementation: Insights from offender management evaluations. Policing, 7(3), 289-298.

Dawson, P., \& Williams, E. (2009). Reflections from a police research unit-An inside job. Policing, 3(4), 373-380.

Flanagan, R. (2008). Final report of the independent review of policing commissioned by the Home Secretary and conducted by Sir Ronnie Flanagan. London: Home Office.

Garfinkel, H. (1964). Studies of the routine grounds of everyday activities. Social problems, 11(3), 225-250.

Hohl, K., \& Stanko, E. A. (2015). Complaints of rape and the criminal justice system: Fresh evidence on the attrition problem in England and Wales. European Journal of Criminology, 1477370815571949.

HMIC. (2011). The rules of engagement: A review of the August 2011 disorders. London: HMIC.

Lum, C., Telep, C., Koper, C., \& Grieco, J. (2012). Receptivity to research in policing. Justice, Research and Policy, 14(1), 1-35.

Metropolitan Police Service. (2011). Four Days in August. London: Metropolitan Police Service.

Reiner, R. (1992). The politics of the police (2nd ed.). London: Harvester Wheatsheaf.

Jennings, W. G., Lynch, M. D., \& Fridell, L. A. (2015). Evaluating the impact of police officer body-worn cameras (BWCs) on response-to-resistance and serious external complaints: Evidence from the Orlando police department (OPD) experience utilizing a randomized controlled experiment. Journal of Criminal Justice, 43(6), 480-486.

Stanko, B., \& Dawson, P. (2013). Reflections on the Offending Histories of those Arrested during the Disorder. Policing, 7(1), 3-11.

Stanko, E., \& Dawson, P. (2015). Police Use of Research Evidence: Recommendations for Improvement.

\section{Biography}

Paul Dawson is the Research Manager in Evidence and Insight, Mayor's Office for Policing And Crime in London. He is a Chartered Psychologist and Associate Fellow of the British Psychological Society. He previously worked within the National Health Service and the Home Office prior to joining the Metropolitan Police Service in 2008. He holds a Ph.D. in Psychology from the University of Birmingham investigating the empirical contribution of weapons to the study of serious sexual offending.

Elizabeth A. Stanko is Head, Evidence and Insight, Mayor's Office for Policing And Crime in London. For over a decade, she worked inside the London Metropolitan Police 
Service, establishing a social research function alongside performance analysis. In her first life, she was a professor of criminology. She was awarded an OBE for her services to policing in the 2014 Queen's Birthday Honours.

\footnotetext{
' using research and scientific processes to inform police decisions' (Lum et al, 2012).

ii Stanko \& Dawson, 2015

iii e.g., see Reiner, 1992; Chan, 1997; Cope, 2004.

iv Stanko \& Dawson, 2015

${ }^{v}$ The current paper focuses upon the Metropolitan Police Service (MPS). We expect a similar position will be in place in most (if not all) police services in the UK.

${ }^{\text {vi }}$ We are not making any judgements about whether this is the 'right' way to work; or even that this work leads to a just outcome. We are saying that this data enables a glimpse of what the organisation is 'doing' and helps frame how it might 'do' better.

${ }^{v i i}$ For example the MPS has completed public surveys in one form or another since the 1980's.

viii This migration was part of a statutory change to the governance of policing across England and Wales.

ix AAMR https://www.london.gov.uk/what-we-do/mayors-office-policing-and-crime-mopac/communitysafety/alcohol-and-substances/sobriety-pilot. BWV http://whatworks.college.police.uk/Research/Documents/Police_Camera_Evidence.pdf

${ }^{\mathrm{x}}$ Both the User Satisfaction Survey and the Public Attitude Survey are available from the University of Essex data archive.

xi Dashboards https://www.london.gov.uk/what-we-do/mayors-office-policing-and-crime-mopac/data-and-research. MOPAC Challenges https://www.london.gov.uk/what-we-do/mayors-office-policing-and-crime-mopac/governanceand-decision-making/mopac-challenge/mopac-challenge-board

xii Global Policing Database https://www.london.gov.uk/press-releases/police-research-database

xiii Hohl and Stanko (2015)

xiv Notably Lum et al (2012).

${ }^{x v}$ Dawson \& Williams, 2009

xvi See Dawson, Goodwill \& Dixon, 2015

xvii Information on the ViCLAS system: http://www.rcmp-grc.gc.ca/tops-opst/bs-sc/viclas-salvac-eng.htm

xviii e.g., See 'Making the Victim Count' HMRC 2014 for a good overview

${ }^{x i x}$ https://www.justiceinspectorates.gov.uk/hmic/wp-content/uploads/crime-recording-chief-inspectors-letter-to-policeforce.pdf

${ }^{\mathrm{xx}}$ Adapted from Stanko and Dawson, 2015

xxi See Flanagan, 2008; Bradley, 2009

xxii Grossmith, L., Franklin-Trespeuch, E., \& Dawson, P. (2013). Mental Health \& the Police: Understanding demand and incident management in the Metropolitan Police Service. Evidence \& Performance internal report.

xxiii http://whatworks.college.police.uk/Research/Pages/Published.aspx

xxiv Jennings, Lynch \& Fridell, 2015

${ }^{x x v}$ See Dawson \& Stanko 2013, Stanko \& Dawson, 2015)

${ }^{x x v i}$ For operational research an arbitrary start date was calculated based upon $50 \%$ of officers in a BWV condition uploading a clip.

xxvii See HMIC, 2011; MPS, 2011; Stanko \& Dawson, 2013.

xxviii as of August 2011

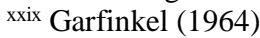

